\title{
Examining Factors Influencing Audit Risk for Professional Accountant in Business
}

\author{
Cheng-Wen Lee ${ }^{1}$ and $\mathrm{Yi}$ Tang $\mathrm{Hu}^{2}$
}

\begin{abstract}
This study attempts to examine the determinant factors influencing the degree of audit risk, specially focusing on the professional accountant in business operations. We adopt the methodology of comprehensive AHP framework combined with DEMATE analysis. Herewith, this study categorizes five main criteria: control environment, risk assessment, audit control, monitoring activities, and information and communication, as well as fifteen sub-criteria. This study result findings may provide some important implications or recommendations for accountant's practice, and meanwhile may contribute suggestions for future researchers' making a breakthrough in theory.
\end{abstract}

JEL classification numbers: C52 M41 M42.

Keywords: Audit risk, Accountant, AHP, DEMATE.

${ }_{1}$ Professor, Department of International Business, Chung Yuan Christian University, Taiwan.

${ }^{2}$ Ph.D program in Business, College of Business, Chung Yuan Christian University, Taiwan. 


\section{Introduction}

Due to the high degree of information technology, accountants must carry out continuous analysis and detection to effectively prevent fraud. At the same time, they must consider the risks of false alarms and the large number of computers generated by individuals in their daily lives or workplaces. Data information is the complexity of Big Data, so company executives must have the ability and timeconsuming to check the authenticity and completeness of transaction sources. According to the definition of the American Accounting Association (AAA), auditing refers to: "through systematic procedures to objectively obtain and evaluate evidence related to economic actions and statements/assertions, to confirm the extent to which these statements meet the established standards, and report the results to stakeholders."

Decision Making Trial and Evaluation Laboratory (DEMATEL) can analyze the correlation between problems to find the primary and secondary issues and further describe the causal relationship between the criteria (Lee et al., 2013). DEMATEL can effectively combine expert knowledge. To clarify the various variables, let the reader know which selection criteria are relatively critical and refer to the more vital and related standards.

\section{Methodology}

\subsection{Operation of DEMATEL}

According to Fontela and Gabus (1976) for DEMATEL's organizational structure and calculation steps, DEMATEL's analysis can be divided into five steps:

1) Define elements and determine relevance

Through literature discussion, brainstorming, and other methods, the system's components can be listed, and their definitions can be defined. The scale of DEMATEL designed by Bolaños et al. (2005) is divided into five levels, in which 0 means very disagree and four standards very agree.

2) Establish a direct relationship matrix

Comparing criterion 1, its influence relationship and degree, when the criterion is stated as $n$, a $n \times n$ matrix can be obtained, which is called the direct relation matrix and is represented by $X$. The number of $X_{i j}$ in the matrix represents the degree to which criterion 1 influences criterion $\mathrm{j}$, and the counter-foot dormitory is set to $Z_{i j}$ as 0 , and the line of $Z$ is as follows:

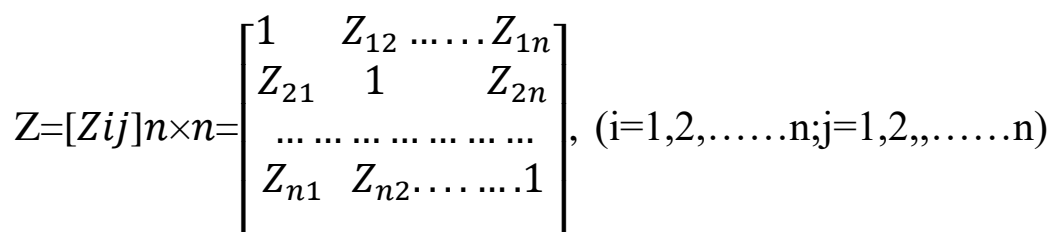


3) Establish a normalized direct relationship matrix

Let $S=\frac{1}{\max _{0 \leqq i \leqq 1}\left(\sum_{J=1}^{n} Z_{i j}\right)}$

and multiply the entire matrix element by $S$ to get the normalized matrix, denoted by $\mathrm{D}$.

$\mathrm{D}=\mathrm{Z} X \mathrm{~S}=\frac{X}{\max _{0 \leqq i \leqq 1}\left(\sum_{J=1}^{n} Z_{i j}\right)}$

4) Calculate Direct/Indirect Matrix

Complete relation matrix $\mathrm{T}=$ direct relation matrix + indirect relation matrix ID, after normalizing the direct matrix, through $\mathrm{T}=\frac{D}{I-D}$ You can calculate the complete relationship matrix $\mathrm{T}$, where $\mathrm{I}$ is the identity matrix in the formula.

From the infinite geometric series,

$\mathrm{T}=\mathrm{D}+\mathrm{ID}=\sum_{i=0}^{\infty} D^{i}=\mathrm{D}+D^{2}+D^{3}+\ldots+D^{\infty}$

Multiply $D$ by left and right to get:

$\mathrm{D} \times \mathrm{T}=D^{2}+D^{3}+D^{4}+\ldots+D^{\infty}+D^{\infty-1}$

(4) minus (5), we get: (I-D) x T=D - $\mathrm{D}^{\infty+1}$. Because the values of the elements of the normalized matrix $\left[d_{i j}\right] n x n$ are all between 0 and $1, D^{\infty+1}=0$ and consequently get: $\mathrm{T}=\frac{D}{I-D}, \mathrm{~T}=t_{i j}, I, \mathrm{j}=1,2 \ldots \mathrm{n}$

5) Draw a cause and effect diagram

Let $t_{i j}(\mathrm{i}, \mathrm{j}=1,2, \ldots . \mathrm{n})$ be the element in $\mathrm{T}$, the sum of each row and the sum of straight rows are expressed by $d_{i}$ and $r_{j}$ respectively, and the following formulas are obtained,

Row sum $\mathrm{d}=d_{n \times 1}=\left[\sum_{j=1}^{n} t_{i j}\right] ;$ Straight summer $=r_{n \times 1}=\left[\sum_{j=1}^{n} t_{i j}\right]_{1 \times n}$ among them,

$d_{i}$ : The sum of other elements affected by the factor I (including direct and indirect effects)。

$r_{j}$ : The sum of elements affected by other factors with element $j$ as a result.

The sum of the ranks $(d+r)$ is called the degree of relevance, which is derived from $\left(d_{k}+r_{k}\right)$, which represents the influence caused by this element, that is, the total degree of influence, which can show the strength of the correlation of this element in the factor group; relatively, The rank difference $(d-r)$ is called the "cause" degree, which is derived from $d_{k}-r_{k}$. If the value of $\left(d_{k}-r_{k}\right)$ is positive. The element is biased as an element type that "will affect" and is classified as "cause." If the value of $\left(d_{k}-r_{k}\right)$ is negative, this element is biased towards the "affected" element and is classified as "fruit." Mark the known $(d+r)$ and $(d-r)$ as coordinates, and the causal diagram uses $\left(d_{k}-r_{k}, d_{k}-r_{k}\right)$. As the pairing coordinates, the horizontal axis is $(d-$ 
$r)$, the vertical axis. It is $(d-r)$. That is, the upper part of the $\mathrm{x}$-axis is classified as a "factor group," and the lower part of the x-axis is classified as a "fruit group." The elements are presented in the form of coordinates. This causality diagram's complex causality is simplified into an easy-to-understand structure, allowing researchers to understand the problem in-depth and provide solutions. Besides, the cause-effect diagram helps decision-makers to plan suitable decisions based on the criteriainfluenced or affected elements. In this study, DEMATEL can convert the degree of interaction between responsible faces or groups into the characteristics of causal diagram relationships to establish the model's relationship structure and introduce the group weight into the AHP step.

\subsection{Analytic Hierarchy Process (AHP)}

1) Basic theory of hierarchical analysis

Saaty (1977) proposed contingency planning issues for the US Department of Defense. With the support of National Science Foundation's funding, Saaty (1988) conducted in-depth research on the rational distribution of electricity in various industries. It was mainly used in uncertainty. Under the circumstances and on decision-making problems with multiple evaluation criteria, the purpose of the development of hierarchical analysis is to systematize complex issues, decompose them at different levels, and find the context through quantitative calculations and make comprehensive evaluations (Saaty, 2003). Saaty (1987) engaged in research on the impact of "No Peace, No War" on Egypt's economic and political conditions for the Egyptian government, and began to standardize relevant judgments. After Saaty (1977) applied the Analytic Hierarchy Method (AHP) to Sudan's transportation research, the whole theory matured. From 1974 to 1978, after continuous application of corrections and proofs, the whole theory became more complete. From 1982 to 1987, three books on AHP theory were successively published. Since the development of AHP, related papers published in international journals have continuously appeared, and the scope of application is also quite extensive (Saaty and Vargas, 2006).

AHP is mainly used in uncertain situations and decision-making problems with multiple evaluation criteria. It converts complex decision-making problems into a hierarchical structure and then uses pairwise comparison. The decision-maker compares the two elements, then uses the eigenvector method to obtain the weights of the details, and conducts the consistency test of the judgment preference at the same time, and finally evaluate the importance of elements. The hierarchical analysis method can also use a tree-like hierarchical structure to divide a complex decision-making problem into several simple sub-problems in one level. Each subproblem can be analyzed independently. The sub-problems in this level can contain any type of sub-problems, whether tangible or intangible, carefully calculated or roughly estimated, clearly understood or vaguely understood, as long as the subproblems used for final decision-making can be included. The evaluation scale systematically gives weight values to each part's relative importance, shows a pair 
of comparison matrix, and calculates the eigenvectors and eigenvalues. The eigenvectors represent the priority of each piece in each level. Therefore, decisionmakers have sufficient decision-making information and organize relevant decision-making criteria or criteria, weights, and analysis, and can reduce the risk of decision errors.

2) Basic assumptions of hierarchical analysis

The basic assumptions of the AHP method mainly include the following nine items:

a) A system can be broken down into many classes or components and form a directed network's hierarchical structure.

b) In the hierarchical structure, the elements of each level are assumed to have independence.

c) The elements in each level can be evaluated using some or all of the previous group features.

d) In comparative evaluation, the absolute numerical scale can be converted into a proportional scale.

e) After pairwise comparison, a positive flu value matrix (positive reciprocal matrix) can be used for processing.

f) The preference relationship satisfies transitivity. Not only the pros and cons relationship satisfies the transitivity ( $\mathrm{A}$ is better than $\mathrm{B}, \mathrm{B}$ is better than $\mathrm{C}$, IJ $A$ is better than $C$ ), but the strong relationship also satisfies the transitivity (A is better than B twice, and B is better than $\mathrm{c}$ three times. IJ A is six times better than $\mathrm{C}$ ).

g) It is not easy to be completely transitive, so non-transitive existence is allowed, but the degree of consistency should be tested.

h) The degree of the advantage of the elements is obtained through the weighting principle.

i) As long as any element appears in the hierarchical structure, no matter how small its degree of advantage is, it is considered to be related to the entire evaluation structure and not to check the hierarchical structure's independence.

3) Levels and elements

Based on the assumption that individuals can form different aggregates, the system elements are included in many levels (groups). Each class only affects another level and is only affected by another level/influence. The system structure is used to study various elements in the level and its impact. The hierarchical structure can be from the overall goal (overall objective). The factors that affect the sub-goals, and the people who influence the factors, people's goals and policies, and the strategies to achieve the goals or policies, finally form multiple levels. The number of classes depends on the complexity of the system and analysis requirements.

4) Dependence and independence

Certain factors limit the ability to deal with complex problems; the concept of 
dependence and independence is an example. It is necessary to consider it when dealing with practice issues (Saaty and Takizawa, 1986). Generally speaking, when dealing with the problem of dependence, because it is not perfect and precise, it is often evaluated and analyzed under the assumption of independence; this simplified process, although the labor (time, labor, money, etc.) spent on processing can be saved, still need to avoid excessive simplification, causing the problem to lose its original appearance.

\section{5) Evaluation scale}

After the establishment of the hierarchical structure, the next step is the evaluation. The assessment of AHP is based on the elements of the previous level at each level as the basis for evaluating the next level's characteristics. In short, it is to assess the relative contribution or importance of the two elements to the benchmark by taking any two pieces at a certain level and the details of the previous story as the benchmark (Kjærsgaard, 2005). As shown in Figure 1, to compare the relative importance of every two elements between claws, ..., Xr, use 0]: as the benchmark, and do $(\mathrm{X} 1, \mathrm{X} 2),(\mathrm{X} 1, \mathrm{X} 3),(\mathrm{X} 2, \mathrm{X} 3)$... and other elements of the comparison between pairs. This process decomposes complex issues into pairwise comparisons, reduces the evaluator's thinking burden, and focuses on the relationship between the two elements.

The assessment scale of AHP is used as a pairwise comparison between each level of index factors. The primary division includes five items, namely, equal strong, weak strong, strong, very Strong. Absolution is given the scales 1, 3, 5, 7, and 9, and four leaves are set between the five essential plates, and the leaves are 2, 4, 6, and 8. In the operation process of the AHP hierarchical analysis method, the first step is to describe the problem, and the following steps include identifying the influential factors, establishing the hierarchical structure, designing the questionnaire items, and finding out the relative importance of the decision-making attributes among the levels, based on the data collected by the questionnaire. Based on the mention above, a paired comparison matrix is established to calculate the eigenvalues and eigenvectors of the matrix. After the data obtained is corrected by the consistency test's feedback and the hierarchical structure consistency test, each index's weight can be calculated to assist in selecting the most suitable decisionmaking plan.

6) Pairwise comparison method

When the hierarchical structure is established, the affiliation of the elements between the upper and lower levels has been determined. According to the hierarchical structure diagram, the second-level q elements have a dominant relationship with the next-level sub-elements. The purpose of the AHP method is to give the corresponding $r$ sub-elements under the element $q$ according to the relative importance of the $r$ sub-elements. However, it is not easy to directly obtain the weights of $r$ sub-elements for most problems that require humans to judge the matter. It is often necessary to derive the consequences through appropriate methods - the 
proper technique used in the AHP method. The process is through the pairwise comparison method in which every two elements are compared with each other, or called the pairwise comparison method.

7) Eigenvalue and eigenvector

In multivariate analysis, it is often necessary to use eigenvalues and eigenvectors for analysis. In addition to discussing the properties of eigenvalues and eigenvectors, this section will also explain eigenvalues and eigenvectors --the concept of the solution and approximate solution method.

\section{8) Consistency verification}

If the pairwise comparison matrix $\mathrm{A}$ is a positive and negative value matrix, it is quite tricky for the decision-maker to achieve consistency when comparing pairwise. Therefore, it is necessary to conduct a consistency test to create a consistency index (Consistency index, CI) to check the pairwise comparison matrix formed by the decision maker's answers. How reasonable is the judgment? Is it not consistent? Or is there a contradiction? Timely Corrections to avoid making bad decisions. The consistency test can be used for the overall hierarchical structure and evaluate decision-maker's or experts' paired judgment matrix under a single evaluation benchmark. Because each level's importance is different, it is necessary to test whether or not the entire hierarchy structure is consistent.

9) Decision-making procedures for applying the AHP method

When dealing with complex problems, it is necessary to use a systematic approach to analyze. The AHP method adheres to this spirit and is a practical and straightforward method in multi-objective or multi-criteria decision-making. The assessment of decision-making problems using the AHP method mainly includes the following three stages of work (Zahedi, 1986):

Phase I: Establish a hierarchy of evaluation

Phase II: Calculation of the weight of each level element

a) Establish a pairwise comparison matrix

b) Obtain eigenvalues and eigenvectors

c) Consistency verification

Phase III: Calculation of the overall level weight

10) Integration of expert preferences

When using the AHP method for decision-making assistance, it is often necessary to rely on the professional judgment and help of experts in different fields to collect the effects of ideas, so it belongs to the category of group decision making or collective decision making. Group decision-making first involves the number of experts. The number of experts is related to the complexity of the decision-making problem. Generally speaking, the number of experts is 5-15. After the number of experts is determined, the next thing this study integrates expert preferences in the decision-making assistance process. 


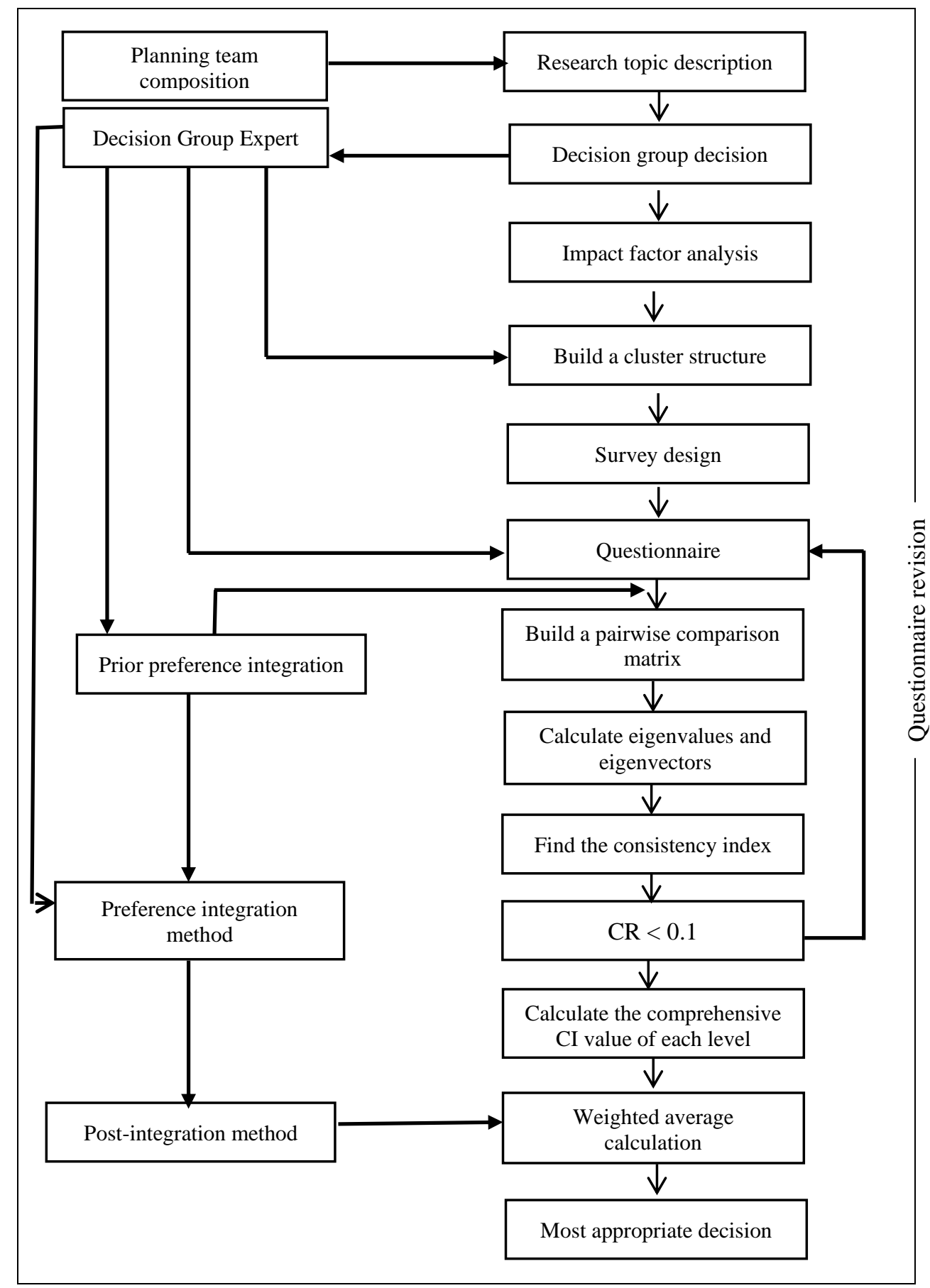

Figure 1: AHP application analysis process 


\subsection{Sampling}

The variable tables previously mentioned in this study are used as the basis for the development of questionnaires. An expert questionnaire is prepared after reviewing by actual accountants and experts, and scholars in other behavioral fields. The accounting firm's accountants are assigned to make predictions to improve the questionnaire's validity and reliability. The accounting firms are the main body of this questionnaire survey, 15 experts are expected to be investigated which will be sent in person, E-MAIL, or fax for the first time. The time for follow-up is limited to two weeks. If the reply was not received, we will visit and follow up continuously. The research subjects are mainly "accountants." The relevant sample statistics are shown in Table 1.

Table 1: Basic information of the sample

\begin{tabular}{|c|c|c|c|}
\hline Feature & Item & Frequency & Percentage \\
\hline \multirow[t]{2}{*}{ Gender } & Male & 7 & 58.33 \\
\hline & Female & 5 & 41.67 \\
\hline \multirow{4}{*}{ Age } & 30 or less & 1 & 8.33 \\
\hline & $31-45$ & 5 & 41.67 \\
\hline & $46-60$ & 4 & 33.33 \\
\hline & 61 or more & 2 & 16.67 \\
\hline \multirow{2}{*}{ Education } & College & 10 & 83.33 \\
\hline & Above research institute & 2 & 16.67 \\
\hline \multirow{3}{*}{$\begin{array}{l}\text { Learning } \\
\text { Courses }\end{array}$} & Department of Accounting and Finance & 10 & 83.33 \\
\hline & Other business departments & 2 & 16.67 \\
\hline & Non-business department & 0 & 0.00 \\
\hline \multirow{2}{*}{$\begin{array}{l}\text { Computer } \\
\text { Information }\end{array}$} & Haven't repaired or studied computer & 10 & 83.33 \\
\hline & Have repaired or studied computer & 2 & 16.67 \\
\hline \multirow{3}{*}{$\begin{array}{l}\text { Practicing } \\
\text { years }\end{array}$} & $1-10$ years & 1 & 8.33 \\
\hline & $11-20$ years & 8 & 66.67 \\
\hline & More than 21 years & 3 & 25.00 \\
\hline \multirow{3}{*}{ Auditors } & $1-100$ & 10 & 83.33 \\
\hline & $101-200$ & 2 & 16.67 \\
\hline & 201 or more & 0 & 0.00 \\
\hline
\end{tabular}

\subsection{Design of research framework and expert questionnaire}

1) Research structure

This study uses literature to discuss the construction of the most appropriate decision analysis that affects audit risk-from the perspective of computer review mechanism, collect documents that have related effects on audit risk, select the relationship of mutual influence through expert questionnaires, and use the DEMATAL method combined with AHP The law combines the two principal directions of material misrepresentation risk and investigation risk and is divided into "Environmental risk," "Control risk," "Policy risk," and "Professional risk." 
"Professional risk," "Information risk," and the other five dimensions are further divided into the most appropriate risk decision criteria that should be selected. They are the total amount of unusual transactions that can be quickly detected by the subject. Because the current management has increased the pressure to manipulate financial information, the subject's manipulation of traditional or substantial earnings risk has reduced, as well as, the user's trust and dependence on financial statements have continued to increase. The issue can reduce operational risks and strengthen the operation of the internal audit department. "Non-GAAP" information enhances the assessment of investors, tax authorities and analysts, and enhances the professional knowledge and skills of accountants. Establishing an appropriate organization and responsibility structure brings about the significant changes to the organizational structure of the accounting firm, and the reduction in the turnover rate of auditors. The ability and attitude of the subject to use big data technological analysis can affect the audit risk. This research framework is shown in Figure 2.

2) Design of the expert questionnaire

This study's results are mainly used as the construction of accountants' most appropriate decision-making analysis for auditing risks-referenced from the viewpoint of computer audit mechanism. Therefore, when selecting experts, this survey mainly aimed at accountants who directly bear audit risks to ensure their suitability to the overall computer audit environment. The expert questionnaire of this study is designed to have two points; one is the questionnaire of the DEMATEL method to understand the causality of the direction and main criteria, and the other is the questionnaire of the AHP method to understand the relative importance of the movement, main criteria, and implementation plan. The questionnaires are combined to draw a general conclusion. The questionnaire design is based on the consideration of fuzzy theory (Zhong and Chao, 2007), and the form of answering questions is presented in a quantitative form. 
Goal

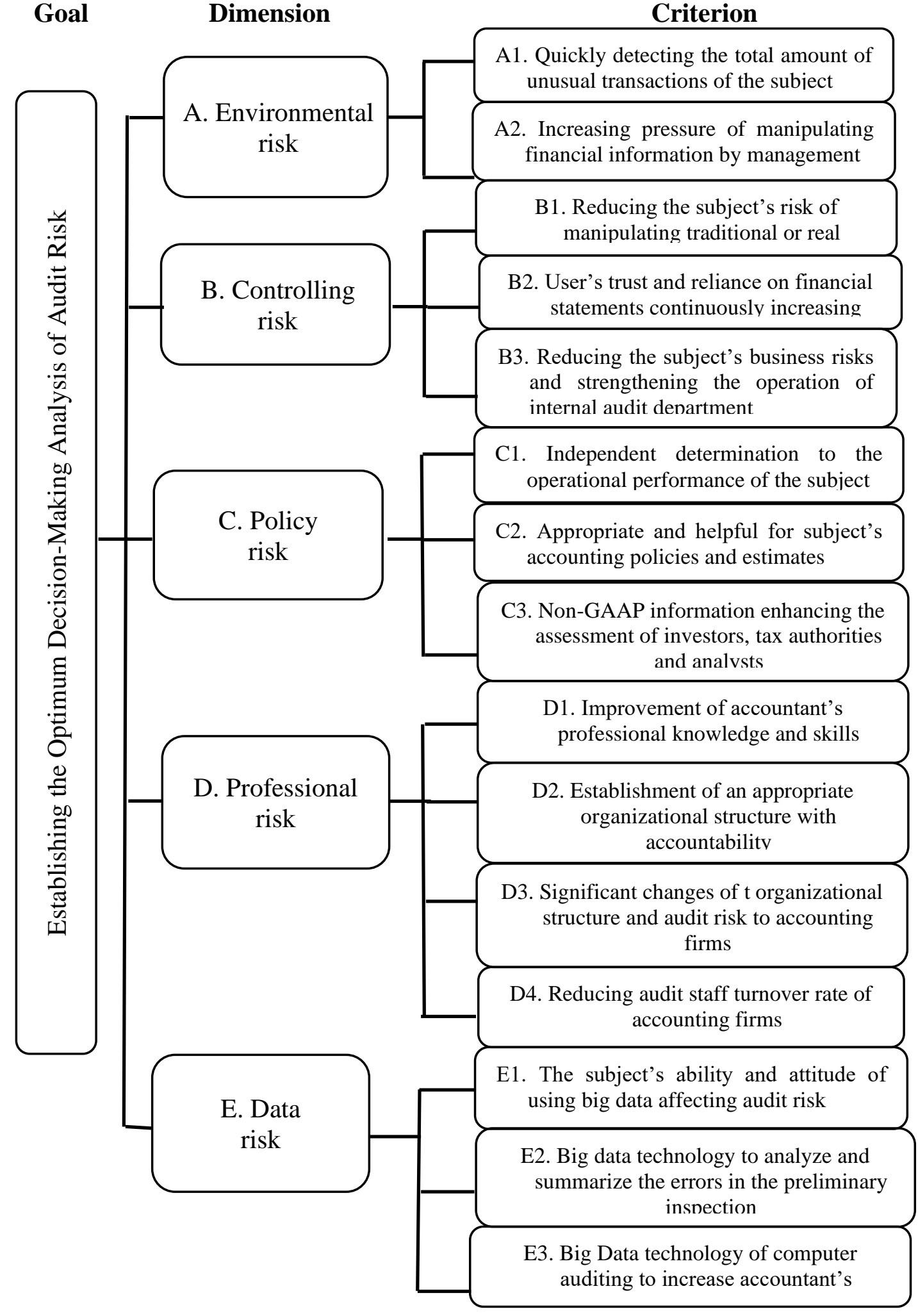

Figure 2: This research framework 


\section{Empirical Analysis}

\subsection{DEMATE analysis}

This study uses the decision-making laboratory (DEMATE) analysis method to analyze the interaction between the selection opinions and the criteria by combining the AHP method (calculation weight) to simulate the most appropriate decisionmaking analysis of audit risk. This research gathered 12 valid questionnaires from experts during November $1^{\text {st }}$ 30th, 2020.

Comparing with the version proposed by Tzeng and Huang (2011), this revised version (Revised DANP) has the following characteristics. Firstly, due to the importance and relative weights of factors generated by DEMATEL and ANP, respectively relative weights can show the importance of factors. Revised DANP, therefore, does not take precedence or relative weight as the only consideration when determining key factors but adopts the method of combining the two messages DEMATEL and ANP jointly determine the key factors. Secondly, Revised DANP uses the total influence matrix to draw the causal diagram of the critical elements, but not all aspects; its advantage is to significantly simplify draw the cause and effect diagram. It is helpful to focus on the critical cause and effect analysis. When a key factor has an arrow pointing to the other key In terms of factors, it means that the former is the critical factor that most affects the latter. In the end, DEMATEL traditionally recognizes that relation and positive values can be classified as cause, and therefore should be the key to the maximum positive value of the factors However, factors with positive causes can only claim that they actively affect other factors, but they may not actually be the beginning of improvement. On the contrary, factors with negative reasons are classified as effects, but they may be without room for improvement. In practice, Revised DANP uses causality diagrams and even further uses Importance-performance analysis (IPA) to determine the starting points, rather than merely relying on the degree of cause.

\subsection{Determination of causality between criteria}

This study uses the DEMATEL method to clarify the causal relationship between the shadow computer audit's factors and criteria. Firstly, by issuing the questionnaire, a direct influence relationship matrix based on the questionnaire results is generated, and then by normalizing the natural influence matrix and entering the formula $\mathrm{T}=\mathrm{X}(\mathrm{I}-\mathrm{X})-1$, the Table 2 Total Influence Matrix $\mathrm{T}$ (Total Influence Matrix). Let $t_{i j}(i, j=1,2, \ldots n)$ be the elements in the total influence relationship matrix $\mathrm{T}$, the sum of the elements in each row 89 is $\mathrm{D}$, and the sum of the elements in each row (column) is R, and D+R is defined as the importance (prominence), the higher the $\mathrm{D}+\mathrm{R}$, the higher the degree of repetition of the criterion. Also, DR is defined as the degree of cause (relation). If the degree of the criterion's cause is positive, it means that the criterion is an active influencer. The larger the DR value, the higher the degree of the direct influence of this factor on other factors. Such criteria can be considered first for improvement; however, if the criterion's cause degree is negative, it means that the criterion is affected. The smaller the value, 
the higher the degree of influence of this factor by other factors. According to the total impact relationship matrix in Table 3, the degree of importance and cause are calculated, as shown in Table 4.

\subsection{Determination of critical factors}

This paper adopts the DANP operation architecture proposed by $\mathrm{Hu}$ et al. (2015) and uses the total influence relationship matrix of DEMATEL as the unweighted supermatrix in the ANP operation. The matrix is normalized, and the normal The transformed results are multiplied by themselves until convergence, and the super limit matrix shown in Table 4 is obtained. The super limit matrix can determine the relative weight of each criterion. For example, the consequences of A1 and A2 are 0.049 and 0.050, respectively. Since DEMATEL and ANP generate information on the importance of standards, when determining key factors, the volume of DEMATEL or the weight of DANP should not be the only consideration. Therefore, this research adopts combining the two pieces of information ( $\mathrm{Hu}$ et al., 2015) to determine the criterion weight ranking. The corresponding criteria' importance and reason are added to the order of the measures weights generated by DANP. The reranking is shown in Table 5. 
Table 2: The total influence matrix

\begin{tabular}{|c|c|c|c|c|c|c|c|c|c|c|c|c|c|c|c|c|}
\hline T & A1 & $\mathbf{A 2}$ & $\mathbf{B 1}$ & $\mathbf{B 2}$ & $\mathbf{B 3}$ & $\mathbf{C 1}$ & $\mathbf{C 2}$ & $\mathbf{C 3}$ & $\mathbf{D 1}$ & $\mathbf{D} 2$ & $\mathbf{D 3}$ & $\mathbf{D 4}$ & $\mathbf{E 1}$ & $\mathbf{E 2}$ & $\mathbf{E 3}$ & $\mathbf{D}$ (effect) \\
\hline A1 & 0.104 & 0.166 & 0.151 & 0.159 & 0.151 & 0.166 & 0.177 & 0.168 & 0.153 & 0.160 & 0.174 & 0.182 & 0.177 & 0.221 & 0.216 & 2.526 \\
\hline A2 & 0.105 & 0.116 & 0.103 & 0.158 & 0.148 & 0.163 & 0.173 & 0.165 & 0.150 & 0.157 & 0.171 & 0.179 & 0.166 & 0.296 & 0.208 & 2.458 \\
\hline B1 & 0.096 & 0.155 & 0.094 & 0.104 & 0.143 & 0.155 & 0.165 & 0.157 & 0.143 & 0.149 & 0.162 & 0.170 & 0.158 & 0.243 & 0.196 & 2.288 \\
\hline B2 & 0.140 & 0.154 & 0.143 & 0.103 & 0.095 & 0.154 & 0.165 & 0.157 & 0.143 & 0.149 & 0.162 & 0.169 & 0.158 & 0.196 & 0.194 & 2.282 \\
\hline B3 & 0.143 & 0.155 & 0.096 & 0.106 & 0.096 & 0.155 & 0.165 & 0.157 & 0.143 & 0.149 & 0.163 & 0.170 & 0.159 & 0.242 & 0.197 & 2.299 \\
\hline C1 & 0.140 & 0.154 & 0.143 & 0.150 & 0.095 & 0.107 & 0.165 & 0.157 & 0.143 & 0.149 & 0.162 & 0.169 & 0.158 & 0.196 & 0.194 & 2.282 \\
\hline C2 & 0.149 & 0.164 & 0.149 & 0.158 & 0.149 & 0.164 & 0.129 & 0.171 & 0.118 & 0.159 & 0.172 & 0.180 & 0.168 & 0.210 & 0.249 & 2.490 \\
\hline C3 & 0.139 & 0.152 & 0.139 & 0.145 & 0.138 & 0.152 & 0.162 & 0.107 & 0.107 & 0.128 & 0.160 & 0.167 & 0.156 & 0.194 & 0.190 & 2.236 \\
\hline D1 & 0.159 & 0.175 & 0.159 & 0.167 & 0.158 & 0.175 & 0.187 & 0.177 & 0.114 & 0.149 & 0.183 & 0.192 & 0.179 & 0.270 & 0.266 & 2.709 \\
\hline D2 & 0.153 & 0.168 & 0.153 & 0.207 & 0.151 & 0.168 & 0.179 & 0.171 & 0.152 & 0.115 & 0.176 & 0.185 & 0.172 & 0.216 & 0.211 & 2.577 \\
\hline D3 & 0.162 & 0.178 & 0.162 & 0.171 & 0.161 & 0.178 & 0.192 & 0.181 & 0.164 & 0.171 & 0.139 & 0.240 & 0.182 & 0.229 & 0.268 & 2.776 \\
\hline D4 & 0.153 & 0.168 & 0.153 & 0.161 & 0.152 & 0.168 & 0.201 & 0.170 & 0.154 & 0.161 & 0.176 & 0.137 & 0.175 & 0.216 & 0.219 & 2.564 \\
\hline E1 & 0.174 & 0.191 & 0.174 & 0.183 & 0.173 & 0.191 & 0.205 & 0.194 & 0.176 & 0.183 & 0.245 & 0.256 & 0.148 & 0.283 & 0.277 & 3.053 \\
\hline E2 & 0.155 & 0.171 & 0.155 & 0.164 & 0.155 & 0.171 & 0.183 & 0.173 & 0.157 & 0.164 & 0.179 & 0.187 & 0.178 & 0.173 & 0.259 & 2.624 \\
\hline E3 & 0.156 & 0.171 & 0.156 & 0.164 & 0.155 & 0.171 & 0.212 & 0.181 & 0.156 & 0.164 & 0.179 & 0.188 & 0.178 & 0.231 & 0.169 & 2.631 \\
\hline R & 2.128 & 2.437 & 2.129 & 2.299 & 2.120 & 2.437 & 2.662 & 2.486 & 2.172 & 2.307 & 2.603 & 2.772 & 2.511 & 3.417 & 3.314 & 37.795 \\
\hline
\end{tabular}


Table 3: Prominence analysis and the relation of criteria

\begin{tabular}{|c|c|c|c|c|c|}
\hline Guidelines & $\begin{array}{c}\text { D } \\
\text { (effect) }\end{array}$ & $\begin{array}{c}\mathbf{R} \\
\text { (affected) }\end{array}$ & $\begin{array}{c}\text { D+R } \\
\text { (Importance) }\end{array}$ & $\begin{array}{c}\text { D-R } \\
\text { (Cause degree) }\end{array}$ & Ranking \\
\hline A1 & 2.53 & 2.13 & 4.65 & 0.40 & 12 \\
\hline A2 & 2.46 & 2.44 & 4.90 & 0.02 & 7 \\
\hline B1 & 2.29 & 2.13 & 4.42 & 0.16 & 15 \\
\hline B2 & 2.28 & 2.30 & 4.58 & -0.02 & 13 \\
\hline B3 & 2.30 & 2.12 & 4.42 & 0.18 & 14 \\
\hline C1 & 2.28 & 2.44 & 4.72 & -0.16 & 11 \\
\hline C2 & 2.49 & 2.66 & 5.15 & -0.17 & 6 \\
\hline C3 & 2.24 & 2.49 & 4.72 & -0.25 & 10 \\
\hline D1 & 2.71 & 2.17 & 4.88 & 0.54 & 9 \\
\hline D2 & 2.58 & 2.31 & 4.88 & 0.27 & 8 \\
\hline D3 & 2.78 & 2.60 & 5.38 & 0.17 & 4 \\
\hline D4 & 2.56 & 2.77 & 5.34 & -0.21 & 5 \\
\hline E1 & 3.05 & 2.51 & 5.56 & 0.54 & 3 \\
\hline E2 & 2.62 & 3.42 & 6.04 & -0.79 & 1 \\
\hline E3 & 2.63 & 3.31 & 5.95 & -0.68 & 2 \\
\hline
\end{tabular}

Table 4: The total influence matrix

\begin{tabular}{|c|c|c|c|c|c|c|c|c|c|c|c|c|c|c|c|}
\hline W & A1 & A2 & B1 & B2 & B3 & C1 & C2 & C3 & D1 & D2 & D3 & D4 & E1 & E2 & E3 \\
\hline A1 & 0.049 & 0.068 & 0.071 & 0.069 & 0.071 & 0.068 & 0.067 & 0.068 & 0.070 & 0.069 & 0.067 & 0.066 & 0.070 & 0.065 & 0.065 \\
\hline A2 & 0.050 & 0.047 & 0.049 & 0.069 & 0.070 & 0.067 & 0.065 & 0.066 & 0.069 & 0.068 & 0.066 & 0.064 & 0.066 & 0.087 & 0.063 \\
\hline B1 & 0.045 & 0.063 & 0.044 & 0.045 & 0.067 & 0.063 & 0.062 & 0.063 & 0.066 & 0.065 & 0.062 & 0.061 & 0.063 & 0.071 & 0.059 \\
\hline B2 & 0.066 & 0.063 & 0.067 & 0.045 & 0.045 & 0.063 & 0.062 & 0.063 & 0.066 & 0.064 & 0.062 & 0.061 & 0.063 & 0.057 & 0.058 \\
\hline B3 & 0.067 & 0.064 & 0.045 & 0.046 & 0.045 & 0.064 & 0.062 & 0.063 & 0.066 & 0.065 & 0.063 & 0.061 & 0.063 & 0.071 & 0.059 \\
\hline C1 & 0.066 & 0.063 & 0.067 & 0.065 & 0.045 & 0.044 & 0.062 & 0.063 & 0.066 & 0.064 & 0.062 & 0.061 & 0.063 & 0.057 & 0.058 \\
\hline C2 & 0.070 & 0.067 & 0.070 & 0.069 & 0.070 & 0.067 & 0.049 & 0.069 & 0.054 & 0.069 & 0.066 & 0.065 & 0.067 & 0.061 & 0.075 \\
\hline C3 & 0.065 & 0.062 & 0.065 & 0.063 & 0.065 & 0.062 & 0.061 & 0.043 & 0.049 & 0.056 & 0.061 & 0.060 & 0.062 & 0.057 & 0.057 \\
\hline D1 & 0.075 & 0.072 & 0.075 & 0.072 & 0.075 & 0.072 & 0.070 & 0.071 & 0.052 & 0.065 & 0.070 & 0.069 & 0.071 & 0.079 & 0.080 \\
\hline D2 & 0.072 & 0.069 & 0.072 & 0.090 & 0.071 & 0.069 & 0.067 & 0.069 & 0.070 & 0.050 & 0.068 & 0.067 & 0.068 & 0.063 & 0.064 \\
\hline D3 & 0.076 & 0.073 & 0.076 & 0.074 & 0.076 & 0.073 & 0.072 & 0.073 & 0.075 & 0.074 & 0.053 & 0.087 & 0.072 & 0.067 & 0.081 \\
\hline D4 & 0.072 & 0.069 & 0.072 & 0.070 & 0.072 & 0.069 & 0.076 & 0.068 & 0.071 & 0.070 & 0.068 & 0.049 & 0.070 & 0.063 & 0.066 \\
\hline E1 & 0.082 & 0.078 & 0.082 & 0.080 & 0.082 & 0.078 & 0.077 & 0.078 & 0.081 & 0.080 & 0.094 & 0.092 & 0.059 & 0.083 & 0.084 \\
\hline E2 & 0.073 & 0.070 & 0.073 & 0.071 & 0.073 & 0.070 & 0.069 & 0.070 & 0.072 & 0.071 & 0.069 & 0.068 & 0.071 & 0.051 & 0.078 \\
\hline E3 & 0.073 & 0.070 & 0.073 & 0.071 & 0.073 & 0.070 & 0.080 & 0.073 & 0.072 & 0.071 & 0.069 & 0.068 & 0.071 & 0.068 & 0.051 \\
\hline
\end{tabular}


Table 5: The overall ranking for criteria

\begin{tabular}{|c|c|c|c|c|}
\hline Attributes & DEMATEL & D-ANP & Sum of sort & Sum of final \\
\hline A1 & 12 & 8 & 20 & 10 \\
\hline A2 & 7 & 10 & 17 & 9 \\
\hline B1 & 15 & 14 & 28 & 15 \\
\hline B2 & 13 & 11 & 24 & 14 \\
\hline B3 & 14 & 12 & 27 & 12 \\
\hline C1 & 11 & 13 & 24 & 11 \\
\hline C2 & 6 & 9 & 15 & 8 \\
\hline C3 & 10 & 15 & 25 & 12 \\
\hline D1 & 9 & 3 & 11 & 5 \\
\hline D2 & 8 & 7 & 16 & 7 \\
\hline D3 & 4 & 2 & 6 & 2 \\
\hline D4 & 5 & 6 & 11 & 5 \\
\hline E1 & 3 & 1 & 4 & 1 \\
\hline E2 & 1 & 4 & 5 & 2 \\
\hline E3 & 2 & 5 & 7 & 2 \\
\hline
\end{tabular}

According to the research results in Table 5, we have obtained eight critical factors for the accountant industry in computer auditing. The importance prioritizing of these factors to the accountant industry in computer auditing is as follows:

E1. The subject's ability and attitude of using big data affecting audit risk Enterprises are highly digitized, which affects the form of obtaining data from the audit review environment. Getting the required data from the enterprise resource planning (ERP) system, self-developed system, or cloud database is a significant challenge, accompanied by transaction volume. With a considerable increase, the verification method will inevitably need to be adjusted. In recent years, the application of data analysis in audit has been promoted. The most widely discussed, such as computer-aided audit, continuous audit (immediate audit), data analysis (Data \& Analysis; D\&A), and other concepts, these digital audits. The application is promoted by accounting firms, subverting the traditional auditing appearance. Whether the subject provides training on employees' integrity, ethics, and professional competence to ensure management policies and control procedures. The integrity of employees in the accounting department of the respondent affects the audit risk. The higher the employee's sense of morality, the lower the audit risk. Whether the respondent is compelling will be distinguished from the employees involved in the financial statements based on their power, which is also a significant risk influencing factor. It is pointed out that $67 \%$ of the interviewees believe that the power division of financial statement personnel will affect inherent risks, and the impact level will reach significantly. It Is also a control variable. Therefore, the 
employees' ability and attitude to use big data technology will affect the control environment and control operations.

D3. Significant changes of t organizational structure and audit risk to accounting firms. The content and specifications involved in the computer audit report are quite complex and receive considerable attention. It has also affected the organizational structure of accountants and has undergone significant changes in the auditing atmosphere. However, in practice, many accountants and computer auditors have increased their responsibilities to prepare statements. For the implementation of audit review, an appropriate structure shall be established by the "Auditing Standards Bulletin No. 48", including considering the main scope of power and responsibility, And proper reporting hierarchy relationship. The appropriateness of the surveyed 's organizational structure depends to some extent on its scale and the nature of its operating activities. Therefore, the division of authority between the inspected departments and the appropriateness of the separation of powers of the internal audit department will affect the risk of the control environment itself and the effectiveness of the operation.

D1. Improvement of accountant's professional knowledge and skills

The increasing improvement of accountants and auditing functions and the growing status of auditing have put forward new auditors' quality requirements. Cultivating a certain number of high-level and high-skilled auditing talents who are proficient in auditing business, master the rules of auditing development, and proficiently use modern auditing techniques and methods are the fundamental way to adapt audit work to the development of the times, keep pace with the times, and maintain longterm vitality. To have a certain degree of business knowledge and ability, not only to be familiar with accounting systems and accounting standards, and to have professional technical knowledge of auditing, but also to have a certain level of understanding, analysis, and judgment.

E3. Big Data technology of computer auditing to increase accountant's challenges As the business environment changes, transaction information faces challenges such as volume, variety, veracity, rapid change, complex laws and regulations, policy procedures, financial constraints, contracts, and internal control procedures of the enterprise. They are also presented digitally. Whether it is financial statement review, compliance review, or operation review, traditional manual audit methods can no longer adapt to this era in the face of vast amounts of data.

E2. Big data technology to analyze and summarize the errors in the preliminary inspection. When the auditors checked the financial statements in the previous period, they found material misrepresentation or fraud, significantly impacting inherent risks and control. In the past, errors in financial statements were the main reason that was identified as a high intrinsic risk; up to $94 \%$ of the interviewees said that there were errors in the previous financial statements, which would affect 
auditors' assessment of reliable risks; errors in accounts receivable and inventories would increase Audit risk.

D2. Establishment of an appropriate organizational structure with accountability Establish an appropriate organization and responsibility structure following "Auditing Standards Bulletin No. 48", including considering the main scope of powers and responsibilities and proper reporting hierarchy. The appropriateness of the subject's organizational structure depends to a certain extent on its scale and the nature of its operating activities. Therefore, the division of authority between the subject's departments and the separation of powers of the internal audit department will affect the risk of the control environment itself and the execution of operations The degree of effectiveness. The larger the subject's company, the higher the business risk they have to bear, and therefore the higher the audit risk.

D4. Reducing audit staff turnover rate of accounting firms

Human resources are the most critical operating resource of an accounting firm. For a long time, a job has faced a high turnover of middle and low-level personnel. The turnover rate of auditors during the busy season has caused significant troubles for the firm's accountants. At present, the accounting firm is facing the traditional (Manual operation). The audit business stagnates and even shrinks the business's bottleneck, so the use of big data technology computer audit is a must. Besides, the turnover rate of critical management and accounting personnel is a factor that affects inherent risks. In the past few years, accounting personnel and management's turnover rate will cause changes in intrinsic risks. As much as $93 \%$ of the research subjects believe that the government has occurred in the past few years. The class's high turnover rate will affect the inherent risk; $89 \%$ of the research subjects believe that the turnover rate of important accountants will affect the inherent risk.

A1. Quickly detecting the total amount of unusual transactions of the subject According to "Audit Bulletin No. 43", auditors should understand the motives and rationality of unusual or irregular significant transactions. The purpose of these transactions is to consider whether these transactions involve fraud in financial reports or the concealment of asset misappropriation. Unusual or unexpected relationships should be regarded as when significant misrepresentation risks caused by fraud. Auditors or companies can use big data technology to detect fraud or unusual transactions and reduce the probability of their occurrence. Therefore, big data technology to see the subject's total amount of unusual transactions will affect risk assessment and information and communication. 


\section{Conclusion and Suggestion}

This research is an exploratory study. The research's primary purpose is to construct a model for the most appropriate decision-making analysis of audit risk and establish a hierarchical structure based on the literature discussion of factors affecting accountant risk assessment by the computer audit mechanism. Future research can use Multiple Criteria Decision Making (MCDM) combined with Decision Making Trial and Evaluation Laboratory (DEMATEL) and Hierarchical Analysis (Analytic Hierarchy Process; AHP) to analyze complex and unstructured. The problem is divided into several components, and they are arranged into a class order. Then the opinions of experts and scholars and the actual participation in decision-making at all levels are gathered. The complex system is simplified into a straightforward element-level design, and the scale of the items is used as the element of each group. The pairwise comparison of and establishing the pairwise comparison matrix, the eigenvector of the matrix is obtained according to the eigenvector. The eigenvector is used as the priority vector of the level, representing the priority order among the elements, and then the eigenvalues. The basis for evaluating the pairwise comparison matrix's consistency is used as an index for decision-making or re-evaluation.

This research hopes to use the DEMATEL + ANP method to explore how to establish a perfect audit risk optimal decision analysis model. This research is an exploratory study. It is hoped that the findings of this research can provide followup researchers with empirical analysis (qualitative or quantification), and the inference of this research can contribute to the accountant industry in creating diversified services and e-commerce (digital information). Judging from the causal diagram of the research results analysis, it is recommended that managers consider first to improve in management.

Unlike traditional IPA, the weight of the standards is replaced by the "Sequence and Total" score. The lower the score, the higher the importance. Since the eight lowest scores are the key factors, the eighth-ranked score of the D2 criterion is 16, and the 9th A2 criterion score is 17 . Therefore, the vertical axis direction's critical value can be set to any value between 16-17. To show the eight critical criteria' performance, this research still uses five experts as the survey subjects.

Regarding the accountant's participation in the eight critical standards of computer auditing, we scored from 0-100 according to the scale. The average of the scores of 12 experts was calculated to obtain the accountant's performance level of the eight key standards of computer auditing. After discussion, all experts agreed to use 70 points as the critical value for judging the performance of the key criteria. If accountants want to obtain the best results in computer audits, they must pay special attention to the criteria that should be maintained continuously. The accounting industry should consider whether there are resources, the phenomenon of displacement.

Although the use of expert interviews and DANP methods to solve multi-criteria decision-making problems has made up for many other ways, this research still has 
some shortcomings and limitations. First of all, because the DANP method requires experts to fill out a large number of cumbersome questionnaires, takes up a lot of experience and time for experts, and requires the cooperation of expert teams, it is worth thinking about whether other simplified multi-criteria decision-making methods can be used, such as the Delphi method (Okoli and Pawlowski, 2004), combination with Grey Relational Analysis (GRA) (Pakkar, 2016). Furthermore, the interviewed expert team is all from Taiwan, so this article's management implications may be limited to providing a reference for Taiwan's accountant industry. Therefore, in the follow-up research, we can strive for more experience data of accountants and auditors at home and abroad to improve this research's international applicability. Nowaday, still just a few journal articles can be referred to this issue. Therefore, we will continue to pay attention to the latest research on this topic and improve the academic value of this article. 


\section{References}

[1] Bolaños, R., Fontela, E., Nenclares, A. and Pastor, P. (2005).Using interpretive structural modelling in strategic decision-making group. Management Decision, 43(6), pp. 877- 895.

[2] Fontela, E. and Gabus, A. (1976). The DEMATEL Observer, DEMATEL 1976 Report. Battelle Geneva Research Center, Switzerland Geneva.

[3] Hu, Y., Wu, Y., Li, Q., Zhang, W. and Jin, C. (2011). Solution structure of yeast Rpn9: insights into proteasome lid assembly. Journal of Biological Chemistry, 290(11), pp. 6878-6889.

[4] Kjærsgaard, J. (2005). Incorporating multiple objectives in fisheries management: Experiences and conceptual implications. (pp. 1-43). København: Fødevareøkonomisk Institut, Københavns Universitet. FOI Working Paper, No. 6, Vol.. 2005

[5] Lee, H.-S., Tzeng, G.-H., Yeih, W., Wang, Y.-J. and Yang, S.-C. (2013). Revised DEMATEL: Resolving the Infeasibility of DEMATEL. Applied Mathematical Modelling, 37(10-11), pp. 6746-6757.

[6] Okoli, C. and Pawlowski, S. D. (2004). The Delphi method as a research tool: An example, design considerations and applications. Information \& Management, 42(1), pp. 15-29.

[7] Pakkar, M.-S. (2016). An integrated approach to grey relational analysis, analytic hierarchy process and data envelopment analysis. Journal of Centrum Cathedra, 9(1), pp.71-86.

[8] Saaty, T. L. (1977). A scaling method for priorities in hierarchical structures. J ournal of Mathematical Psychology, 15(3), pp. 234-281.

[9] Saaty, T. L. (1988). What is the analytic hierarchy process? Mathematical Models for Decision Support, pp. 109-121. Springer, Berlin, Heidelberg.

[10] Saaty, T. L. (2003). Decision-making with the AHP: Why is the principal eigenvector necessary. European Journal of Operational Research, 145(1), pp. 85-91.

[11] Saaty, T. L. and Takizawa, M. (1986), Dependence and independence: From linear hierarchies to nonlinear networks. European Journal of Operational Research, 26(2), pp. 229-237.

[12] Saaty, T. L. and Vargas, L. G. (2006). Decision Making with the Analytic Network Process. Springer Science+ Business Media, LLC.

[13] Saaty, R.W. (1987). The analytic hierarchy process: What it is and how it is used. Mathematical Modelling, 9(3-5), pp. 161-176.

[14] Tzeng, G. and Huang, J. (2011). Multiple Attribute Decision Making Methods and Applications. CRC Press, Taylor and Francis Group, A Chapman \& Hall Book.

[15] Zhong, L. and Youchao, S. (2007). Research on maintainability evaluation model based on fuzzy theory. Chinese Journal of Aeronautics, 20(5), pp. 402407. 